\title{
EVALUASI KEADILAN PRAKTIK TUNJANGAN KINERJA PADA KEPUASAN DAN KINERJA KARYAWAN DI KANTOR BPS DIY
}

\author{
Heru Kurnianto Tjahjono \\ Universitas Muhammadiyah Yogyakarta \\ e-mail: heruutilitas@yahoo.com \\ Riniarti \\ PNS BPS DIY
}

\begin{abstract}
The purpose of this study was to test and analyze the performance benefits of aspects of justice on the satisfaction and the performance of civil servants in BPS DIY. Specifically, this research examines and analyzes the influence of distributive justice and procedural justice on satisfaction of performance benefits and performance of civil servants in BPS DIY. This study uses census by taking the entire population of civil servants in BPS DIY as responden. Analisis data using SEM with AMOS program. The results showed that distributive justice and procedural justice performance benefits have positive effect on satisfaction and only procedural justice has positive influence on the performance of civil servants in BPS DIY. Results also showed that the performance benefits satisfaction mediates the effect of distributive justice on the performance of civil servants in BPS DIY.
\end{abstract}

Keywords: performance benefits, distributive justice, procedural justice, satisfaction and performance

\begin{abstract}
Abstrak
Tujuan penelitian ini adalah menguji dan menganalisis pengaruh tunjangan kinerja dari aspek keadilan pada kepuasan dan kinerja PNS di BPS DIY. Secara spesifik penelitian ini menguji dan menganalisis pengaruh keadilan distributif dan keadilan prosedural pada kepuasan dari tunjangan kinerja yang diterima dan kinerja PNS di BPS DIY. Penelitian tersebut menggunakan metode sensus dengan mengambil seluruh populasi PNS di BPS DIY sebagai responden. Analisis data menggunakan SEM dengan program AMOS. Hasil menunjukkan bahwa keadilan distributif dan keadilan prosedural tunjangan kinerja berpengaruh positif pada kepuasan dan sebagian di antaranya berpengaruh positif pada kinerja PNS di BPS DIY. Hasil juga menunjukkan bahwa kepuasan tunjangan kinerja memediasi pengaruh keadilan distributif pada kinerja PNS di BPS DIY.
\end{abstract}

Kata kunci: tunjangan kinerja, keadilan distributif, keadilan prosedural, kepuasan dan kinerja.

\section{PENDAHULUAN}

Tunjangan kinerja merupakan tambahan pendapatan bagi pegawai berbasis pada kinerja pegawai. Tujuan diterapkan tunjangan kinerja adalah untuk meningkatkan motivasi, kepuasan dan kinerja karyawan tersebut. Di lingkungan PNS (Pegawai Negeri Sipil), tunjangan kinerja diterapkan untuk meningkatkan kepuasan dan kinerja para karyawan sehingga organisasi publik tersebut dapat memberikan pelayanan publik secara lebih baik.

Isu penting terkait tunjangan kinerja adalah apakah sudah diterapkan berbasis pada nilai-nilai keadilan. Artinya, apakah tunjangan kinerja telah dipraktikkan secara adil mendasarkan pada kinerja pegawai dengan mendasarkan pada metode tertentu yang dianggap dapat mendorong produktivitas atau kinerja karyawan?

Teori keadilan distributif merupakan bagian dari teori motivasi yang disebut dengan equity theory di mana orang mengevaluasi kontribusi yang diberikan pada organisasi dan apa yang mereka peroleh dari organisasi, kemudian dibandingkan dengan karyawan lain yang dinilai dapat diperbandingkan. Sedang- 
kan, keadilan prosedural merupakan keadilan atas mekanisme munculnya alokasi keadilan distributif. Terkait dengan keadilan, maka dapat diartikan bahwa keadilan kompensasi adalah persepsi pegawai mengenai adil atau tidaknya pembayaran yang mereka terima dibandingkan dengan prestasi kerja. Dalam studi eksperimennya, Tjahjono (2011) menjelaskan bahwa keadilan dapat meningkatkan kepuasan kerja, dimana hal ini akan memotivasi pegawai untuk meningkatkan kinerja mereka.

Secara konseptual, tunjangan kinerja PNS dinilai sebagai bagian kompensasi yang berhubungan erat dengan kinerja (Tjahjono, 2005). Oleh karena itu keadilan tunjangan kinerja PNS baik dari sisi distribusi maupun prosedural akan mempengaruhi kepuasan dan kinerja PNS. Selanjutnya dalam konteks praktik, tujuan penelitian ini adalah menguji dan menganalisis pengaruh keadilan distributif dan keadilan prosedural tunjangan kinerja pada kepuasan dan kinerja PNS di BPS Provinsi D.I. Yogyakarta.

\section{KAJIAN PUSTAKA}

\section{Pengaruh Keadilan Distributif pada Outcome}

Keadilan distributif adalah keadilan berkaitan dengan alokasi outcome atau hasil yang diperoleh karyawan (Folger \& Konovsky, 1989; Masterson et al., 2000). Tjahjono (2008a; 2008b; 2010; 2011 dan 2014) menambahkan bahwa keadilan distributif bersifat transaksional dan berpengaruh pada kesejahteraan karyawan. Hal tersebut sejalan dengan pandangan Clayton dan Opotow (2003).

Dalam pandangan Tyler (1994) ketika orang bekerja pada organisasi, maka kesejahteraan mereka tergantung pada distribusi sumberdaya di dalam organisasi, dimana pandangan tersebut dikenal dengan pendekatan sumberdaya (resource-based model). Hal tersebut dikuatkan penelitian Tjahjono (2008a; 2008b; 2011 \& 2014) bahwa alokasi yang diperoleh karyawan dari organisasi bersifat subjektif personal, yaitu orang mempunyai kecenderungan menilai keadilan berjalan baik apabila hasil yang mereka harapkan sesuai dengan yang diberikan organisasi.

Secara empiris, penelitian terdahulu menjelaskan bahwa keadilan distributif berdampak pada outcomes seperti kepuasan dan kinerja (Folger \& Konvsky, 1989; McFarlin \&
Sweeney, 1992; Sweeney \& McFarlin, 1993; Tang \& Baldwin, 1996; Skarlicky \& Folger, 1997; Colquitt, 2001; Colquitt et al., 2001; Viswesvaran \& Ones, 2002; Tjahjono, 2010; 2011; 2014; Palupi, 2013; Palupi et al., 2014). Dengan demikian, hipotesis penelitian dalam setting kebijakan tunjangan kinerja di BPS DIY sebagai berikut:

H1: Keadilan distributif tunjangan kinerja berpengaruh positif pada kepuasan dari tunjangan kinerja yang diterima PNS BPS DIY.

$\mathrm{H} 2$ : Keadilan distributif tunjangan kinerja berpengaruh positif pada kinerja PNS BPS DIY.

\section{Pengaruh Keadilan Prosedural pada Outcome}

Keadilan prosedural menjelaskan bahwa orang tidak hanya melakukan evaluasi hasil, namun juga melakukan evaluasi prosedur untuk menentukan alokasi tersebut (Taylor et al, 1995; Tyler \& Blader, 2003). Hal tersebut dijelaskan Thibaut \& Walker (1978) berbasis pada kepentingan pribadi dan Lind \& Tyler (1988) berbasis pada nilai-nilai kelompok.

Secara empiris, sejumlah penelitian telah menjelaskan bahwa keadilan prosedural berdampak positif pada outcomes seperti kepuasan dan kinerja (Folger \& Konvsky, 1989; McFarlin \& Sweeney, 1992; Sweeney \& McFarlin, 1993; Tang \& Baldwin, 1996; Skarlicky \& Folger, 1997; Colquitt, 2001; Colquitt et al., 2001; Viswesvaran \& Ones, 2002; Tjahjono, 2010; 2011; 2014; Palupi, 2013; Palupi et al., 2014 ). Dengan demikian, hipotesis penelitian dalam setting kebijakan tunjangan kinerja di BPS DIY sebagai berikut:

H3: Keadilan prosedural tunjangan kinerja berpengaruh positif pada kepuasan dari tunjangan kinerja yang diterima PNS BPS DIY.

H4: Keadilan prosedural tunjangan kinerja berpengaruh positif pada kinerja PNS BPS DIY.

Dalam perspektif teori-teori isi (conteni) maka pemenuhan kepuasan akan men dorong pada peningkatan motivasi yang lebih tinggi. Hal tersebut dipaparkan Maslow dan Aldelfer (lihat Kinicky \& Fugate, 2013) bahwa pemenuhan kebutuhan pada level individu ini 
berdampak pada sejumlah perilaku dan outcomes positif termasuk di dalamnya adalah kinerja individu. Hal tersebut diperjelas Kincky \& Fugate (2013) bahwa kepuasan kerja adalah sikap yang menjadi kunci utama dalam bekerja sehingga manajemen berusaha untuk meningkatkan kinerja karyawan melalui kepuasan kerja. Dengan demikian hipotesis penelitian dalam setting kebijakan tunjangan kinerja di BPS DIY sebagai berikut:

H5: Kepuasan dari tunjangan kinerja yang diterima berpengaruh positif pada kinerja PNS BPS DIY.

\section{Model Penelitian}

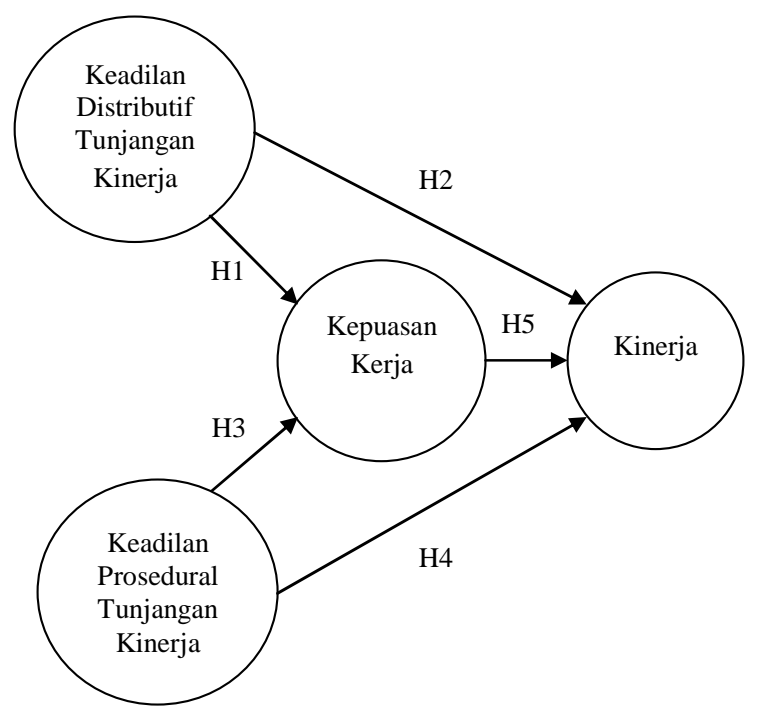

Gambar 1. Kerangka Pemikiran Teoritis

\section{METODE PENELITIAN}

Pendekatan dalam penelitian ini adalah kuantitatif dengan menggunakan survei. Pengumpulan data penelitian dilakukan secara sensus dengan mengambil data seluruh pegawai pada Badan Pusat Statistik Provinsi Daerah Istimewa Yogyakarta yaitu sebanyak 64. Jumlah sampel ini tidak memenuhi asumsi SEM mengenai ukuran sampel. Oleh karena itu dilakukan bootstrapping. Bootstraping yang digunakan adalah bootstraping Maximum Likelihood (ML).

Setelah dilakukan prosedur bootstrap, maka akan dilakukan evaluasi kesesuaian model menggunakan The Bollen-Stine Bootstrap. Sampel yang diambil untuk bootstrap ini sebanyak 500 sampel (default), dengan BollenStine bootstrap $\mathrm{p}=0.776$. Pada model original tanpa bootstrap hasilnya sama dengan ketika dilakukan bootstrap. Jika hasil etimasi parameternya masih konsisten dengan hasil estimasi tanpa bootstrapping maka model penelitian tanpa bootstrapping masih layak untuk digunakan.

\section{Definisi Operasional dan Variabel Penelitian}

Definisi operasional variabel-variabel yang akan diteliti disajikan pada tabel 1 .

\section{Pengujian Validitas}

Uji validitas dilakukan dengan tujuan mengetahui ketepatan kuesioner yang mempunyai arti bahwa kuesioner mampu mengukur apa yang seharusnya diukur. Suatu kuesioner dikatakan valid jika pertanyaan pada kuesioner tersebut mampu untuk mengungkapkan sesuatu yang akan diukur oleh kuesioner tersebut (Jogianto, 2004).

Berdasarkan hasil uji validitas menunjukkan bahwa semua indikator memiliki loading factor $<0,50$ sehingga hasil perhitungan tersebut telah memenuhi validitas atau dinyatakan valid.

\section{Pengujian Reliabilitas}

Reliabilitas adalah indeks yang menunjukkan seberapa besar suatu alat pengukur dapat dipercaya atau dapat diandalkan. Dalam penelitian ini, reliabilitas adalah ukuran konsistensi internal dari indikator-indikator sebuah variabel bentukan yang menunjukkan derajat sampai dimana masing-masing indikator itu mengidentifikasikan sebuah variabel bentukan yang umum. Rumus yang digunakan untuk menguji reliabilitas menggunakan rumus:

$$
\text { Construct Reliability }=\frac{\left(\sum \text { Std. Loading }\right)^{2}}{\left(\sum \text { Std. Loading }\right)^{2}+\sum \in i}
$$

Hasil empiris dapat dilihat pada Tabel 2 yang menunjukkan bahwa keseluruhan item reliabel atau konsisten sebagai alat ukur.

Uji normalitas dilakukan dengan tujuan untuk mengetahui bagaimana distribusi data pada masing-masing variabel penelitian (Hair et al, 1998). Pengujian tersebut dilakukan dengan menggunakan nilai critical ratio skewness data yang digunakan. Apabila nilai CR (critical ratio) pada skewness data berada pada rentang antara +/- 2,58 pada tingkat signifikansi 0,05 maka data dikatakan terdistribusi secara normal. 
Tabel 1: Definisi Operasional Variabel

\begin{tabular}{|c|c|c|}
\hline Variabel & Definisi & Sumber \\
\hline Kinerja & $\begin{array}{l}\text { Kinerja adalah hasil kerja baik kualitas maupun } \\
\text { kuantitas yang dicapai oleh seseorang pegawai dalam } \\
\text { melaksanakan tugasnya sesuai dengan tanggung jawab } \\
\text { yang diberikan kepadanya }\end{array}$ & $\begin{array}{l}\text { FGD dipandu Tjahjono } \\
\text { dan Riniarti }\end{array}$ \\
\hline Kepuasan Kerja & $\begin{array}{l}\text { Keadaan emosional yang positif yang merupakan hasil } \\
\text { dari evaluasi pengalaman kerja sesorang. Variabel } \\
\text { kepuasan kerja menggambarkan kesesuaian harapan } \\
\text { yang timbul dengan imbalan yang didapatkan dari } \\
\text { pekerjaannya. }\end{array}$ & $\begin{array}{l}\text { Roberts \& Reeds, } 1996 \\
\text { dimodifikasi Tjahjono, } \\
2011\end{array}$ \\
\hline $\begin{array}{l}\text { Kedilan Distributif } \\
\text { Kompensasi }\end{array}$ & $\begin{array}{l}\text { Keadilan Distributif merupakan keadilan atas hasil yang } \\
\text { diterima individu berdasar hasil kerja mereka }\end{array}$ & Tjahjono, 2007 \\
\hline $\begin{array}{l}\text { Kedilan Prosedural } \\
\text { Kompensasi }\end{array}$ & $\begin{array}{l}\text { Keadilan Prosedural merupakan keadilan yang dirasakan } \\
\text { individu dalam hubungannya dengan prosedur atau } \\
\text { aturan dalam pengambilan kebijakan dalam organisasi. }\end{array}$ & Tjahjono, 2007 \\
\hline
\end{tabular}

Tabel 2: Hasil Uji Reliabilitas

\begin{tabular}{lll}
\hline \multicolumn{1}{c}{ Variabel } & $\boldsymbol{C . R}$. & Keterangan \\
\hline $\begin{array}{l}\text { Keadilan distributif dan prosedural } \\
\text { Keadilan distributif tunjangan kinerja }\end{array}$ & 0.837 & Reliabel \\
Keadilan prosedural tunjangan kinerja & 0.912 & Reliabel \\
Outcomes & & \\
Kepuasan Kerja & 0.926 & Reliabel \\
Kinerja & 0.847 & Reliabel \\
\hline
\end{tabular}

Sumber : Data Primer diolah

\section{HASIL DAN DISKUSI}

\section{Analisis Deskriptif Variabel Penelitian}

Analisis deskriptif variabel merupakan gambaran variabel yang diperoleh berdasarkan jawaban responden mengenai pertanyaan/pernyataan yang didasarkan pada indikator yang akan diteliti. Kecenderungan jawaban responden akan dilihat untuk semua variabel penelitian. Kategori masing- masing variabel ditentukan dengan terlebih dahulu membuat interval kelas dengan rumus:

$$
i=\frac{\text { Range }}{2 \text { aKategori }}=\frac{5-1}{3}=1,33
$$

Range dan kategori berdasarkan perhitungan interval kelas tersebut, dapat dilihat pada tabel berikut:
Tabel 3: Kategori Interpretasi Deskriptif

\begin{tabular}{cc}
\hline Range & Kategori \\
\hline $1-2,33$ & Rendah \\
$2,34-3,67$ & Cukup \\
$3,68-5,00$ & Tinggi \\
\hline
\end{tabular}

Berdasarkan kategori pada Tabel 3, variabel dalam penelitian ini akan ditentukan dengan cara menghitung rata-rata hitung (mean) untuk setiap variabel penelitian dan hasilnya akan dikelompokkan dalam kategori yang mana dari tabel interpretasi diatas. Hasil menunjukkan bahwa semua variabel penelitian memiliki nilai rata-rata di atas 3,9 yang artinya semua variabel penelitian termasuk dalam katagori interpretasi tinggi. Secara garis besar dapat dirangkum perolehan nilai skor mean dan kategori interpretasi untuk masing-masing variabel penelitian sebagaimana ditampilkan pada tabel di bawah ini:

Tabel 4: Kategori Variabel

\begin{tabular}{lcc}
\hline \multicolumn{1}{c}{ Variabel } & Mean & Kategori \\
\hline Keadilan distributif tunjangan kinerja & 3.9750 & Tinggi \\
Keadilan prosedural tunjangan kinerja & 3.9152 & Tinggi \\
Kepuasan tunjangan kinerja & 3.9187 & Tinggi \\
Kinerja karyawan & 4.0558 & Tinggi \\
\hline
\end{tabular}

Sumber : Data Primer diolah 
Tabel 4 di atas menunjukkan bahwa secara umum praktik tunjangan kinerja di BPS DIY dipersepsikan adil baik secara distributif dan prosedural. Demikian pula kepuasan karyawan terhadap tunjangan kinerja yang mereka peroleh relatif tinggi. Kategori lainnya adalah kinerja individual yang mereka persepsikan secara umum tinggi.

\section{Analisis Structural Equation Modelling (SEM)}

\section{Uji Model Goodness of Fit}

Pengujian terhadap hipotesis model menunjukkan bahwa Goodness-of fit terhadap data yang digunakan dalam penelitian seperti terlihat indikator Chi-Square, CMIN/DF, RMSEA, CFI,TLI berada pada batas rentang nilai yang disarankan berarti model fit atau diterima. Beberapa indikator yaitu Chi-Square-significance probability, GFI, RFI dan NFI diterima namun masuk dalam kriteria marginal fit. Sedangkan AGFI dalam kriteria tidak fit. Dengan demikian, dapat dikatakan bahwa model diterima. Hasil uji model goodness of fit secara keseluruhan dapat dilihat dalam tabel 5.

\section{Full Model Struktural}

Hasil Pengolahan data untuk analisis full model SEM ditampilkan pada gambar 2.

Tabel 5: Kesesuaian Model (Goodness of Fit)

\begin{tabular}{lccc}
\hline \multicolumn{1}{c}{$\begin{array}{c}\text { Pengukuran } \\
\text { Goodness-of-fit }\end{array}$} & $\begin{array}{c}\text { Batas Rentang Nilai } \\
\text { Yang Disarankan }\end{array}$ & Nilai & Keputusan \\
\hline Chi-Square hitung & $\begin{array}{c}X^{2} \text { hit }<X^{2} \text { Tabel } \\
(d f: 246=286,779)\end{array}$ & $283,586<286,779$ & Fit \\
Chi-Square-significance probability & $\geq 0.05$ & 0.038 & Marginal Fit \\
CMIN/DF (Normed chisquare) & $<2$ & 1,166 & Fit \\
GFI & $\geq 0.90$ & 0,769 & Marginal Fit \\
RMSEA & $\leq 0.08$ & 0,051 & Fit \\
AGFI & $\geq 0.90$ & 0,669 & Tidak Fit \\
RFI & $\geq 0.90$ & 0,745 & Marginal Fit \\
CFI & $\geq 0.90$ & 0,959 & Fit \\
NFI & $\geq 0.90$ & 0,773 & Marginal Fit \\
TLI & $\geq 0.90$ & 0,954 & Fit \\
\hline
\end{tabular}

Sumber : Data Primer diolah 2015

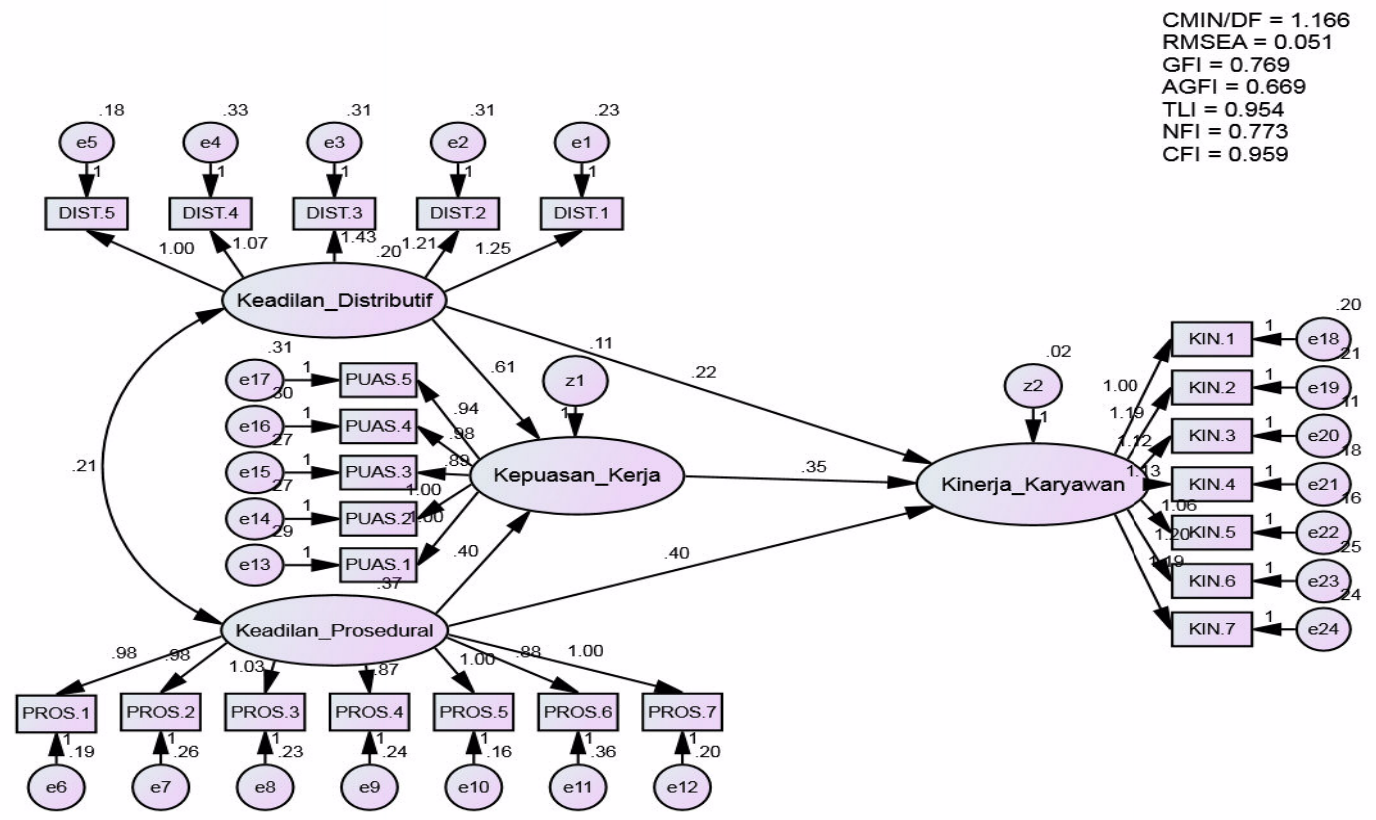

Gambar 2: Gambar Full Model 


\section{Pengujian Hipotesis}

Tabel 6: Hasil Pengujian Hipotesis

\begin{tabular}{|c|c|c|c|c|}
\hline & Hipotesis & Estimate & p-value & Ket. \\
\hline H1 & $\begin{array}{l}\text { Keadilan distributif tunjangan kinerja } \rightarrow \text { Kepuasan_tunjangan } \\
\text { kinerja }\end{array}$ & 0,610 & 0,044 & Signifikan \\
\hline $\mathrm{H} 2$ & Keadilan distributif tunjangan kinerja $\rightarrow$ Kinerja Pegawai & 0,216 & 0,206 & $\begin{array}{c}\text { Tidak } \\
\text { Signifikan }\end{array}$ \\
\hline H3 & $\begin{array}{l}\text { Keadilan prosedural tunjangan kinerja } \rightarrow \text { Kepuasan_tunjangan } \\
\text { kinerja }\end{array}$ & 0,399 & 0,050 & Signifikan \\
\hline $\mathrm{H} 4$ & Keadilan prosedural tunjangan kinera $\rightarrow$ Kinerja Pegawai & 0,398 & 0,001 & Signifikan \\
\hline H5 & Kepuasan Kerja $\rightarrow$ Kinerja Pegawai & 0,349 & 0,009 & Signifikan \\
\hline
\end{tabular}

Sumber : Data Primer diolah

Keterangan:Signifikan pada level 5\%

Berdasarkan model fit tersebut akan dilakukan pengujian terhadap 5 (lima) hipotesis yang diajukan dalam penelitian ini. Pengujian hipotesis didasarkan pada nilai $p$-value dari suatu kausalitas sebagai hasil pengolahan SEM yang secara ringkas tercantum pada tabel 6 .

Sejalan dengan penelitian terdahulu, keadilan distributif tunjangan kinerja PNS di BPS DIY berpengaruh positif pada kepuasan dari tunjangan kinerja yang diterima. Dengan demikian, hipotesis 1 dalam penelitian ini didukung secara empiris. Demikian pula H3 dan H4 menjelaskan bahwa keadilan prosedural berpengaruh positif pada kepuasan dari tunjangan kinerja yang diterima dan kinerja PNS di BPS DIY. Sedangkan pengaruh kepuasan tunjangan kinerja pada kepuasan PNS BPS di DIY juga didukung dalam penelitian ini. Namun demikian $\mathrm{H} 2$ yang menjelaskan bahwa keadilan distributif berpengaruh positif pada kinerja PNS BPS di DIY tidak didukung secara empiris.

\section{Pengaruh keadilan distributif tunjangan kinerja pada kepuasan dan kinerja}

Hasil penelitian menunjukkan bahwa keadilan distributif tunjangan kinerja berpengaruh positif pada kepuasan dari tunjangan kinerja yang diterima. Hasil ini sejalan dengan studi awal keadilan distributif bahwa pada dasarnya karyawan berafiliasi dengan organisasi atau perusahaan agar mereka sejahtera. Apabila kesejahteraan terpenuhi secara adil berkaitan dengan alokasi distribusi maka karyawan tersebut merasa nyaman dan puas. Hasil sejalan dengan penelitian terdahulu yang menjelaskan bahwa keadilan distributif berdampak pada outcomes seperti kepuasan dan kinerja (Folger
\& Konvsky, 1989; McFarlin \& Sweeney, 1992; Sweeney \& McFarlin, 1993; Tang \& Baldwin, 1996; Skarlicky \& Folger, 1997; Colquitt, 2001; Colquitt et al., 2001; Viswesvaran \& Ones, 2002; Tjahjono, 2010; 2011; 2014; Palupi, 2013; Palupi et al., 2014)

Namun secara empiris, hasil penelitian menunjukkan bahwa keadilan distributif tidak berpengaruh pada kinerja. Hasil lain menunjukkan bahwa kepuasan dari tunjangan kinerja yang diterima berpengaruh positif pada kinerja. Kedua hasil tersebut menjelaskan bahwa sebenarnya hasil empiris tersebut tidak terlalu berbeda dengan kajian sebelumnya. Hasil justru menunjukkan bahwa pengaruh positif keadilan distributif pada kinerja terjadi melalui mediasi kepuasan dari tunjangan kinerja yang diterima. Dengan demikian, studi tersebut menjelaskan adanya peran mediasi kepuasan dari tunjangan kinerja yang diterima terhadap pengaruh keadilan distributif tunjangan kinerja pada kinerja PNS.

\section{Pengaruh keadilan prosedural tunjangan kinerja pada kepuasan dan kinerja.}

Hasil penelitian empiris menunjukkan bahwa keadilan prosedural tunjangan kinerja berpengaruh positif pada kepuasan dari tunjangan kinerja yang diterima. Demikian pula keadilan prosedural tunjangan kinerja juga berpengaruh positif pada kinerja PNS. Hasil penelitian ini sejalan dengan penelitian terdahulu yang menjelaskan bahwa keadilan prosedural berdampak pada outcomes seperti kepuasan dan kinerja (Folger \& Konvsky, 1989; McFarlin \& Sweeney, 1992; Sweeney \& McFarlin, 1993; Tang \& Baldwin, 1996; Skarlicky \& Folger, 1997; Colquitt, 2001; Colquitt et al., 2001; 
Viswesvaran \& Ones, 2002; Tjahjono, 2010; 2011; 2014; Palupi, 2013; Palupi et al., 2014). Prosedur yang adil menggambarkan kapabilitas organisasi yang lebih profesional sehingga dapat mengakomodasi kepentingan jangka pendek dan jangka panjang PNS.

\section{PENUTUP}

Kesimpulan hasil penelitian ini menjelaskan bahwa praktik tunjangan kinerja berdampak penting pada kepuasan dan kinerja karyawan. Aspek keadilan distributif, dan keadilan prosedural tunjangan kinerja berpengaruh positif pada kepuasan dari tunjangan kinerja yang diterima dan kinerja karyawan. Hasil juga menunjukkan adanya peran mediasi kepuasan dari tunjangan kinerja yang diterima terhadap pengaruh keadilan distributif pada kinerja karyawan PNS di BPS DIY.

Hasil deskriptif menunjukkan bahwa praktik tunjangan kinerja BPS DIY relative baik. Hal tersebut dapat dilihat pada empat aspek, meliputi: keadilan distributif dan prosedural tunjangan kinerja, kepuasan dari tunjangan kinerja yang diterima dan kinerja PNS BPS DIY relatif tinggi.

Penelitian ke depan perlu menggali aspek-aspek kepribadian karyawan untuk menjelaskan model keadilan pada outcomes di dalam organisasi, karena persepsi keadilan sangat erat hubungannya dengan subjektifitas personal.

\section{DAFTAR PUSTAKA}

Clayton, S. \& Opotow, S. 2003. Justice and identity: changing perspectives on what is fair. Personality and Social Psychology Review, 7(4): 298-310.

Colquitt, J.A., Conlon, D.E., Wesson, M.J., Porter, C. \& Ng, K.Y. 2001. Justice at the millennium: a meta-analytic review of 25 years of organizational justice research. Journal of Applied Psychology, 86(3); 425-445.

Colquitt, J.A. 2001. On the dimensionality of organizational justice: a construct validation of measure. Journal of Applied Psychology, 86(3): 386-400.

Folger, R. \& Konovsky, M.A. 1989. Effects of procedural and distributive justice on reactions to pay raise decisions. Academy of Management Journal, 32(1): 115-130.

Hair, J.F., Anderson, R.E., Tatham, R.L. \& Black, W.C. 1998. Multivariate Data Analysis. New Jersey: Prentice-Hall, Inc.

Jogiyanto, H.M. 2004. Metodologi Penelitian Bisnis: Salah Kaprah dan Pengalaman-Pengalaman. Yogyakarta: BPFE Universitas Gadjah Mada.

Kinicki, A. \& Fulgate, M. 2013. Organizational Behavior. $5^{\text {th }}$ Edition. McGraw Hill Education

Lind, E.A. \& Tyler, T.R. 1988. The Social Psychology of Procedural Justice. New York: Planum.

Masterson, S.S., Lewis, K.,Goldman, B.M. and Taylor, M.S. 2000. Integrating justice and social exchange: the differing effects of fair procedures and treatment on work relationships. Academy of Management Journal, 43(4); 738-748.

McFarlin, D.B. \& Sweeney, P.D. 1992. Distributive and procedural justice as predictors of satisfaction with personal and organizational outcomes. Academy of Management Journal, 35(3): 626637.

Palupi, M. 2013. Pengaruh keadilan kompensasi, kebijakan rotasi, karyawan dan komitmen afektif pada perilaku retaliasi PNS dikantor $\mathrm{X}$ di Yogyakarta."Jurnal riset manajemen dan bisnis. Volume 8 No.1

Palupi, M., Tjahjono, H.K. \& Nuri, R. 2014. Pengaruh keadilan distributif karir dan keadilan prosedural karir terhadap perilaku retaliasi karyawan swasta di Daerah Istimewa Yogyakarta (DIY) dengan kepuasan karir sebagai variabel pemediasian. Jurnal Universitas Paramadina, 11(2): 1095-1109.

Roberts, G.E. \& Reed, T. 1996. Performance appraisal participation, goal setting and feedback. Review of Public Personnel Administration. Fall: 29-60. 
Skarlicky, D.P. \& Folger, R. 1997. Retaliation in the work place: the role of distributive, procedural and interactional justice. Journal of Applied Psychology, 82(3): 434-443.

Sweeney, P.D. \& McFarlin, D.B. 1993. Workers' evaluation of the "Ends" and the "Means": an examination of four models of distributive and procedural justice. Organizational Behavior and Human Decision Processes, (55):2340.

Tang, T.L. \& Baldwin, L.J. 1996. Distributive and procedural justice as related to satisfaction and commitment. Sam Advanced Management journal, 25-31.

Taylor, M.S., Tracy, K.B., Renard, M.K., Harrison, J.K. \& Carroll, S.J. 1995 Due process in performance appraisal: a quasi-experiment in procedural justice. Administrative Science Quarterly. 40: 495-523.

Thibaut, J. \& Walker, L. 1978. A theory of procedure. California Law Review, 66: 541-566.

Tjahjono, H.K. 2005. Praktik-praktik manajemen SDM strategik; pengujian universalistik dan kontijensi dalam menjelaskan kinerja organisasional. Jurnal Bisnis dan Ekonomi Kinerja, 9(2):123134.

Tjahjono, H.K. 2007. Validasi item-item keadilan distributif dan keadilan prosedural: aplikasi structural equation modeling dengan cofirmatory factor analysis (CFA). Jurnal Akuntansi dan Manajemen STIE YKPN, 18(2): 115123.

Tjahjono, H.K. 2008a. Pengaruh keadilan organisasional terhadap perilaku retaliasi (balas dendam) ditempat kerja. Buletin Ekonomi, 6(1): 12-19.

Tjahjono, H.K, 2008b. Studi Literatur Pengaruh Keadilan Distributif dan Keadilan Prosedural pada Konsekuensinya dengan Teknik Meta Analisis. Jurnal Psikologi Volume 35(1),21-40, Universitas Gadjah Mada Yogyakarta.

Tjahjono, H.K. 2010. The extension of twofactor model of justice: hierarchical regression test and sample split. ChinaUSA Business Review, 9(7): 39-54.

Tjahjono, H.K. 2011. The configuration pattern distributive and procedural justice and its consequences to satisfaction. International Journal of Information and Management Sciences, 22(1): 87103.

Tjahjono, H.K. 2014. The fairness of organization's performance appraisal, social capital and the impact toward affective commitment. International Journal of Administrative Science \& Organization, 21(3): 173-179.

Tyler, T.R. 1994. Psychological models of the justice motive: Antecedents of distributive and procedural justice. Journal of Personality and Social Psychology, 67(5):850-863.

Tyler, T.R. \& Blader, S.L. 2003. The group engagement model: procedural justice, social identity, and cooperative behavior. Personality and Social Psychology Review, 7(4):349-361.

Viswesvaran, C. \& Ones, D.S. 2002. Examining the construct of organizational justice: A Meta-Analytic evaluation of relations with work attitudes and behaviors. Journal of Business Ethics, 38: 193-203. 